\title{
Frequency of Mucocutaneous Manifestations of Asthma in Paediatric Patients Aged 2-14 Years
}

${ }^{1}$ Lubna Riaz, ${ }^{2}$ Ammara Kaleem, ${ }^{1}$ Asfand Tariq, Ameer Aslam, ${ }^{1}$ Muhammad Aslam

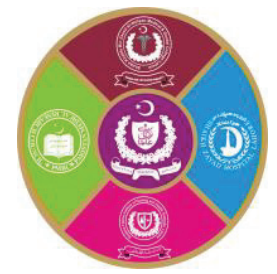

${ }^{1}$ Department of Pediatrics, Shaikh Zayed Medical Complex, Lahore

${ }^{2}$ Department of Pediatrics, Azra Naheed Medical College, Lahore

${ }^{3}$ Department of Pediatrics, CMH Medical \& Dental College, Lahore

\begin{abstract}
Introduction: Bronchial asthma is a major cause of pediatric morbidity and mortality, accounting for over 180,000 of all deaths worldwide. Wide variations exist in the symptom prevalence of childhood asthma worldwide. Allergic mucocutaneous manifestations including allergic rhinitis, eczema and allergic conjunctivitis are variably associated with asthmatic patients. Aims \& Objectives: To determine the frequency of mucocutaneous manifestations of asthma amongst the asthmatic children in the age range of 214 years and their association with family history. Place and duration of study: This retrospective study was conducted for a period of three months in Pediatric Department of Shaikh Zayed Medical Complex. Material \& Methods: A total of 110 children, between 2-14 years of either gender with bronchial asthma for at least 12 months were included in the study from the record of the asthmatic patients. These patients were included from the Department of Pediatric Medicine, Sheikh Zayed Hospital, Lahore. Subjects were divided into two groups according to age, gender and family history. All the demographic data for age, gender and family history were entered in a predefined questionnaire. It was entered in a spreadsheet and then analyzed using the software SPSS version 17.0. Chi square test was applied to find the significance amongst the variables. Results: Asthma was more common in males $(n=64)$ as compared to females $(n=46)$. Most of the patients were between the age group of 2-8 years (73.6\%). Rhinitis was the major associated factor amongst the three, 48(43.6\%). Patients with eczema were 24(21.8\%). Conjunctivitis was noticed in $19(17.3 \%)$. P value was significant $<0.05$ for the eczema in association with positive family history. Conclusion: We concluded that allergic rhinitis, conjunctivitis and eczema were associated with asthma but their prevalence is reduced in our region as compared to international data. Most commonly found manifestation in our study was rhinits and among all of these manifestation eczema was associated with family history.
\end{abstract}

Key words: Bronchial asthma in children, conjunctivitis, rhinitis, eczema, atopy and family history.

\section{INTRODUCTION}

A sthma is a common chronic disease, causing considerable morbidity. Worldwide childhood asthma appears to be increasing in prevalence despite considerable improvements in our management and pharmacopeia to treat asthma. Numerous studies conducted in different countries have reported an increase in asthma prevalence 50\% per decade. Asthma prevalence is correlated well with allergic rhino conjunctivitis and atopic eczema. Approximately $80 \%$ of all asthmatic patients report disease under 6 years. ${ }^{1}$

World Health Organization reports that between 100 and 150 million people around the globe suffer from asthma and this number is rising. World-wide, deaths from this condition have reached over 180,000 annually. ${ }^{2}$
Rhinitis is frequently associated in asthmatic children. ${ }^{3}$ The frequency of rhino-conjunctivitis is higher in cases with more severe asthma symptoms. A study conducted at Isra University Hospital Hyderabad showed childhood asthma was strongly associated with a family history of asthma and allergic rhinitis. ${ }^{4}$ In a cross sectional study conducted at Peru, it was revealed that allergic rhinitis was present in $66.4 \%$ of population with asthma. $^{5}$ In a Brazilian cross sectional study amongst asthmatics, adolescents allergic rhinitis was reported in $46.5 \%{ }^{6}$

In a cross sectional study conducted in Brazil out of 1459 asthmatic children a physician diagnosis of conjunctivitis was registered in $15.8 \%$, but $43.9 \%$ had at least one ocular symptom that suggested ocular allergy. ${ }^{7}$ Atopic dermatitis is a prerequisite for the development of allergic rhinitis and asthma ${ }^{8}$ Atopic dermatitis precedes asthma in $45 \%$ children with asthma. ${ }^{9}$ Another cross sectional study to 
determine the rate of association of rhino conjunctivitis ${ }^{10}$ and asthma symptoms in adolescents showed that among the rhinitis-bearing adolescents, almost $81.3 \%$ had persistent asthma whereas $31.8 \%$ of the asthmatic patients had rhino conjunctivitis. ${ }^{3} \mathrm{~A}$ case control study on the association of rhinitis, eczema and asthma revealed that Sixty percent of subjects with asthma suffered from rhinitis, $29.1 \%$ and $15.7 \%$ associated with allergic conjunctivitis and atopic dermatitis respectively. ${ }^{11}$

In Pakistan, there is no population based study published on this issue. This study is aimed at determining the frequency of these mucocutaneous manifestation in pediatric asthmatic patients in our population and association of these manifestations with age, gender and family history. Our results are expected different from the above mentioned studies. This study will therefore be helpful in early treatment of these manifestations and hence prevention of severity of asthma and further recurrence of asthma amongst our pediatric population.

\section{MATERIAL AND METHODS}

This was a three months cross-sectional retrospective study conducted in 2018 based on data collected between December 2015 and January 2016 Sample size: The sample size is estimated as 110 cases of asthma using 95\% confidence level, 7\% margin of error taking as expected percentage of conjunctivitis as $15.8 \%$ in asthmatic patients.

Sample technique: Non probability consecutive sampling.

Inclusion criteria: All asthmatic patients of 2-14 years of age of both sexes (for atleast 12 months as per operational definition).

\section{Exclusion criteria:}

1. Patients with pneumonia characterized by cough ( $\geq 10$ days), fever ( $\geq 99 \mathrm{~F}^{\circ}$ and respiratory distress

2. Recurrent chest infection characterized by 3 or more episodes of cough, fever and respiratory distress 3 or more episodes in last 12 months

3. Patients having heart failure due to any respiratory or cardiac condition characterized by Tachypnea $\quad(\geq 60 /$ minute $), \quad$ tachycardia (100/minute), hepatomegaly (pulsatile liver) without fever.

Data collection procedure:

Variables: Age, gender, family history, frequency of rhinitis, conjunctivitis and eczema.

Methods for collection of data: Study is approved from Ethical Committee of Shaikh Zayed hospital Lahore. Hundred and ten patients of asthma were collected from the records of the ICU, pediatric emergency, OPD and ward, in Shaikh Zayed hospital Lahore, fulfilling the inclusion criteria, were enrolled in the study. Outcome variables i.e. age, gender frequency of allergic, rhinitis, conjunctivitis and eczema and association with family history were labelled as per operational definition. All the data was entered into predesigned proforma.

\section{Statistical analysis:}

Whole data was subjected to interpretation using a computer software program SPSS (Statistical package for Social Sciences) version 17. Quantitative variables like age, gender, family history, frequency of allergic rhinitis, conjunctivitis, eczema and association of these manifestations with family history are presented by mean and standard deviation. Data stratified for age, gender and family history to deal with effect modalities. Post stratification chi-square test applied $\mathrm{P}$ value $\leq 0.05$ considered significant.

\section{RESULTS}

Total number of 110 patients were selected according to the sample size fulfilling the inclusion and exclusion criteria. These patients were stratified into two groups according to age, gender, presence of conjunctivitis, rhinitis, eczema and family history. First group included the patients from 2 to 8 years. Second group included patients from 9 to 14 years. First group had $81(73.6 \%)$ patients whereas $2^{\text {nd }}$ group had $29(26.4 \%)$ patients (Table- 1$)$. Fortysix $(41.8 \%)$ patients were female and $64(58.2 \%)$ patients were male.

Rhinitis was the most frequent mucocotaneous manifestation with asthma collected in our study $(43.6 \%)$ and eczema was the second one $(21.8 \%)$ (Table-1).

Among the three manifestations only eczema was associated with positive family history ( $\mathrm{p}$ value: 0.015) (Table 2).

\begin{tabular}{|c|c|c|c|c|}
\hline Factors & Frequency & Percent & Mean & SD \\
\hline \multirow[t]{2}{*}{ Age: } & 81 & 73.6 & & \\
\hline & 29 & 26.4 & & \\
\hline \multirow[t]{2}{*}{ Gender: } & 64 & 58.2 & & \\
\hline & 46 & 41.8 & & \\
\hline \multirow{2}{*}{ Conjunctivitis: } & 19 & 17.3 & & \\
\hline & 91 & 82.7 & 1.83 & .380 \\
\hline \multirow[t]{2}{*}{ Rhinitis: } & 48 & 43.6 & & \\
\hline & 62 & 56.4 & 1.56 & .498 \\
\hline \multirow[t]{2}{*}{ Eczema: } & 24 & 21.8 & & \\
\hline & 86 & 78.2 & 1.78 & .415 \\
\hline Family History: Yes & 45 & 40.9 & & \\
\hline No & 65 & 59.1 & 1.59 & .494 \\
\hline Total & 110 & 100 & & \\
\hline
\end{tabular}

Table-1: Frequency of mucocutaneous manifestations with age gender and family history 


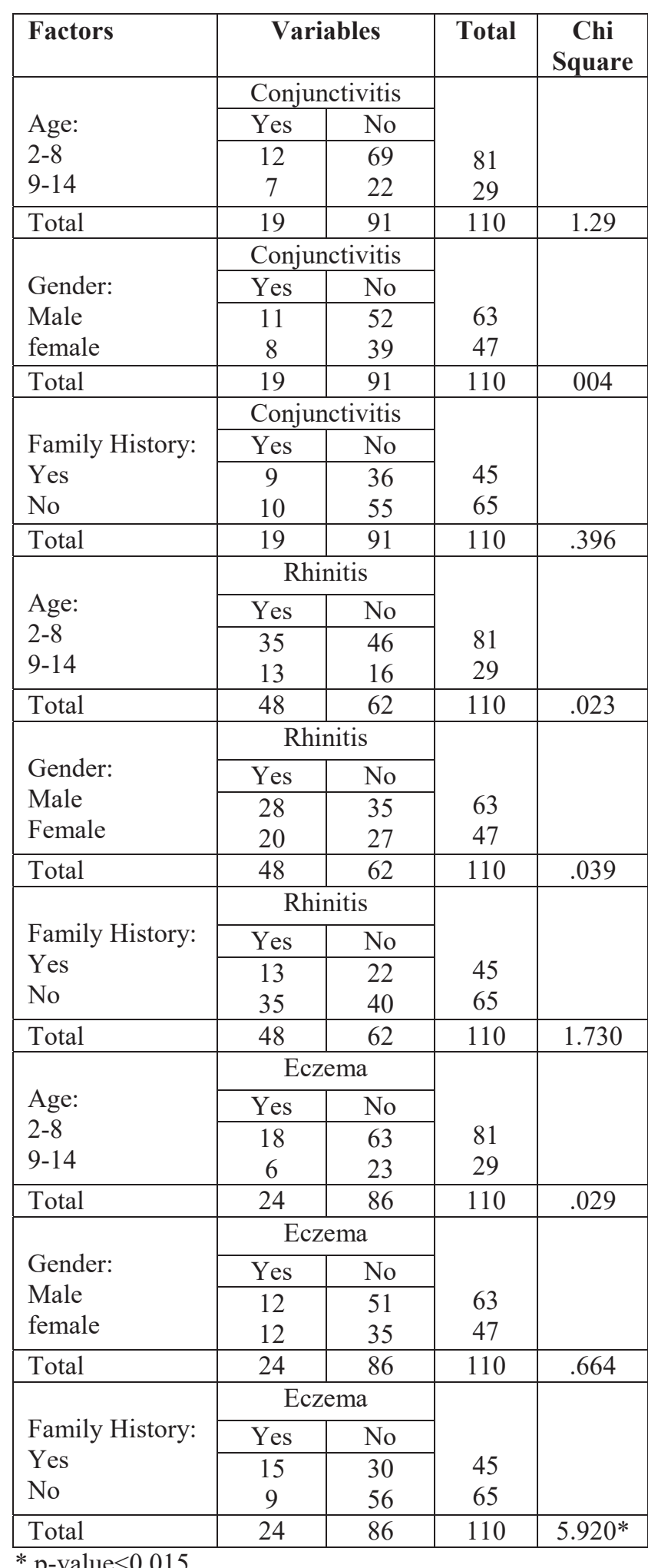

Table-2: Association of factors age gender and family history with mucucotoaneous manifestations

\section{DISCUSSION}

Asthma is a major public health problem worldwide. In Pakistan over 6 million people suffer from asthma. ${ }^{12}$ Pakistan's largest city, Karachi constitutes about $8-10 \%$ population, which suffers from chronic asthma and every $250^{\text {th }}$ death in the city is due to severe asthma exacerbations. ${ }^{12}$ As the prevalence of asthma varies in different countries of the world due to different epidemiological factors. ${ }^{13,14}$ Our aim of the study was to review the mucocutaneous manifestations of asthma i.e. allergic rhinitis, conjunctivitis and eczema and its association with age, gender and family history in our population.

Asthma was more common in males $(n=64)$ as compared to females $(n=46)$ and mostly patients were between the age range of $2-8$ years $(73.6 \%)$ which was different from the age ranges (6-7yrs. and 10-14 yrs.) given in the international data ${ }^{15,16}$.

Rhinitis was the major associated factor among three, $43.6 \%(n=48)$ but the association is low as compared to studies done internationally, where in various cross-sectional studies reveal that rhinitis is highly prevalent among asthmatics ranging from 49 to $79 \%$, and severity of rhinitis is positively associated with asthma severity. ${ }^{17,18}$, We found no data regarding association of allergic rhinitis with asthma in Pakistani children however various studies done locally describe the prevalence of rhinitis and asthma separately. Frequency of allergic conjunctivitis was proved to be $17.3 \% \quad(n=19)$ whereas previously it varies from 15 to $29 \% .^{7,11}$

Atopic dermatitis in asthmatic children also varies from 15 to $45 \%{ }^{6,11}$ in international data. In our study $21.8 \%$ had eczema. Family history of asthma and allergic diseases have been linked to the risk of asthma. ${ }^{19,20}$ A recent article showed that family history of asthma is a strong determinant of developing asthma through childhood and into young adulthood. ${ }^{21}$ In our study $40.9 \%(n=45)$ had positive family history of asthma. However data from studies done at Hyderabad and Karachi variable association of family history with asthma $(70 \%)^{4}$ and $36.4 \%$ respectively. ${ }^{15}$ A case-control study in Lahore reported that 56 (44.8\%) patients gave family history of asthma. ${ }^{22}$ Family history of asthma is presented in $(n=15) 45 \%$ cases of eczema which is significant association revealed in our study in contradiction to international data which showed strong association of rhinits with family history. ${ }^{23}$ But in most of the studies rhinits was found to be associated with RSV infection in children. ${ }^{24}$

We realized there were some limitations in our study. Firstly, the environmental factors like smoking, air pollution, repeated viral infections, vaccination, malnutrition, dietary habits, socioeconomic group and food allergies were not assesed. Secondly status of atopic sensitization to allergens were not included. 


\section{CONCLUSION}

The current study assessed the mucocutaneous manifestations that are allergic rhinitis, conjunctivitis and eczema are associated with pediatric asthmatic patient though their prevalence is variable as compared to international data.This is most likely due to different regional genetic variations, eating habits, vaccination, nutritional status, weather and socioeconomic pattern. The coexistence of atopic manifestations with strong family history in asthmatic patients was related to poor prognosis and early diagnosis could reduce morbidity and burden of disease. Thus, rhinitis is most prevalent in our setup as compared to eczema, while a high risk of eczema was found in patients with a strong family history of asthma.As there was no previous study conducted in Pakistan, so our findings are primary and some other trials are required to validate our finding. Some more studies are required to detect the prevalence of asthma and frequency of these mucocutaneous manifestations with epidemiological risk factors.

\section{Acknowledgment:}

I would like to express my special thanks of gratitude to Mohammad Raahim Ahsan, Araiz Naji and Mohammad Ayaan Siddiqui for their help in data collection and analysis in completing this project.

\section{REFERENCES}

1. StantoBF, SchorNF, Gemi11 JWS. Behrman RE. Nelson Textbook of Pediatrics19 ${ }^{\text {th }}$ ed. India: Reed Elsvier India Private Limited; 2012.781-2.

2. Asthma [internet] [Updated 2013 Nov; cited $2014 \mathrm{Feb} 4$ ]. Available from:

http://www.who.int/mediacentre/factsheets/fs20 6/en/

3. Brito RC, Silva GA, Motta ME, Brito MC. The association of rhino conjunctivitis and asthma symptoms in adolescents. Revistaportuguesa de pneumologia 2009; 15(4): 613-28.

4. Majeed R, Rajar UD, Shaikh N, Majeed F, Arain AA. Risk Factors Associated with Childhood Asthma. JCPSP. 2008;18(5):299-302

5. Padillaj. Uceda M, Ziegler O, Lindo F Perez EH, Huicho L. Association between allergic rhinitis and asthma control in Peruvian school children: a cross sectional study. BioMed Research international. 2013. ID.861213.

6. Andrade CR, Ibiapina CC, Alvim CG, Fontess MJ, Lasmar LM, Camargos PA. Asthma and allergic rhinitis comorbidity: a cross sectional study on adolescents aged 13-14 years. primary care respiratory journal 2008; 17(4):222-5 .

7. Neto HJ, Rosario NA, Westphal GL, Riedi CA, Santos HL. Allergic conjunctivitis in asthmatic children: as common as underreported. Annals of allergy, asthma \& immunology. 2010; 105:399-400.

8. Zheng T, Yu J, Oh MH, Zhu Z. The Atopic March: Progression from Atopic Dermatitis to Allergic Rhinitis and Asthma. Allergy Asthma Immunol Res. 2011; 3(2):67-73.

9. Sokolovski, lazov. 709 atopic dermatitis and family history of allergic diseases in asthmatic and no asthmatic children. Pediatric research 2010; 68:360.

10. Burgess JA, Dharmage SC, Byrnes GB, Matheson MC, Gurrin LC, Wharton CL et al. Childhood eczema and asthma incidence and persistence: a cohort study from childhood to middle age. The Journal of Allergy and Clinical Immunology. 2008; 122(2):280-5

11. Wafy SM Shaaban H, El-Monem EA, Mousa M. Asthma, Rhinitis and eczema association: among school children in Assiut. Egyptian Journal of chest. 2012; 61(1) :17-29.

12. Khan IA, Arsalan MH, Siddiqui MF, Zeeshan S, Shaukat SS. Spatial Association of Asthma and Vegetation in Karachi: A Gis Perspective. Pak. J. Bot 2010; 42(5): 3547-54.

13. Majeed R, Rajar UDM, Shaikh N, Majeed F, Arain AA. Risk Factors Associated with Childhood Asthma. JCPSP. 2008;18(5):299-302

14. Kamran A, Hanif S, Murtaza G. Risk factors of childhood asthma in children attending Lyari General Hospital. JPMA 2015; 65: 647-50.

15. Marks G, Pearce N, Strachan D, Asher I. Global burden of disease due to asthma: Global asthma report 2014:16-21.

16. lai CK, Beasley R, Crane J, Foliaki S, Shah J, Weiland S. global variation in the prevalence and severity of asthma symptoms: phase three of the international study of asthma and allergies in childhood (ISAAC). Thorax 2009 Jun; 64(6):476-83.

17. Leynaert B, Neukirch C, Kony S, Guenegou A, Bosquet J, Aubier M, Neukirch F. Association between asthma and rhinitis according to atopic sensitization in a population-based study. J Allergy Clin Immunol 2004; 113(1):86-93.

18. Hong S, Son D, Lim W, Kim S, Kim H, Yum et al, (2012). The Prevalence of Atopic Dermatitis, Asthma, and Allergic Rhinitis and the Comorbidity of Allergic Diseases in Children. Environmental Health and Toxicology, [online] 
27. Available at: http://e-eht.org/ [Accessed 15 Aug. 2016].

19. London SJ, Gauderman JW, Avol E, Rappaport EB, Peters JM: Family history and the risk of early-onset persistent, early-onset transient, and late-onset asthma. Epidemiology. 2001; 12(5): 577-583.

20. Litonjua AA, Carey VJ, Burge HA, Weiss ST, Gold DR: Parental history and the risk for childhood asthma. Does mother confer more risk than father? Am J Respir Crit Care Med 1998, 158(1):176-181

21. Paaso EMS, Jaakkola MS, Lajunen TK, Hugg TT, Jaakkola JJK: The Importance of Family History in Asthma during the First 27 Years of Life. Am J RespirCrit Care Med.2013;188:624-26

22. Rathore AW, Randhawa SM, Quratulain, Sajid M. wheezing conditions in early childhood: prevalence and risk factors among preschool children. Ann King Edward Med Coll. 2005; 11:14-6.

23. Ballardini N, Bergstrom A Wahlgren CF, et al. Ige antibodies in relation to prevalence and multimormbidity of eczema, asthma and rhinitis birth to adolosence. Allergy. 2016; 72:342-9.

24. Sawicki GS, Smith L, Bokhour B, et al. Periodic use of inhaled steroids in children with mild persistant asthma: what are pediatricians recommending? Clin Pediatr (Phila). 2008; 47: 446-51.

\section{The Authors:}

Dr. Lubna Riaz

Assistant Professor,

Department of Pediatrics,

Shaikh Zayed Medical Complex, Lahore.

Dr. Ammara Kaleem

Senior Registrar, Department of Pediatrics, Azra Naheed Medical College, Lahore.

Dr. Asfand Tariq

Assistant Professor,

Department of Pediatrics,

Shaikh Zayed Medical Complex, Lahore.

Ameer Aslam,

$3^{\text {rd }}$ Year MBBS Student,

CMH Medical College, Lahore.

Prof. Muhammad Aslam

Head of Pediatrics Department, Shaikh Zayed Medical Complex, Lahore.

\section{Corresponding Author:}

Dr. Lubna Riaz

Assistant Professor,

Department of Pediatrics,

Shaikh Zayed Medical Complex, Lahore.

E-mail: lubnariaz15@gmail.com 